\title{
Incorporation of albumin fusion proteins into fibrin clots in vitro and in vivo: comparison of different fusion motifs recognized by factor XIIla
}

\author{
William P Sheffield ${ }^{1,2^{*}}$ and Louise J Eltringham-Smith ${ }^{1}$
}

\begin{abstract}
Background: The transglutaminase activated factor XIII (FXIIIa) acts to strengthen pathological fibrin clots and to slow their dissolution, in part by crosslinking active $\alpha_{2}$-antiplasmin ( $\left.\alpha_{2} A P\right)$ to fibrin. We previously reported that a yeast-derived recombinant fusion protein comprising $\alpha_{2} A P$ residues 13-42 linked to human serum albumin (HSA) weakened in vitro clots but failed to become specifically incorporated into in vivo clots. In this study, our aims were to improve both the stability and clot localization of the HSA fusion protein by replacing $\alpha_{2}$ AP residues 13-42 with shorter sequences recognized more effectively by FXIlla.

Results: Expression plasmids were prepared encoding recombinant HSA with the following N-terminal 23 residue extensions: $H_{6} N Q E Q V S P L T L L A G_{4} Y$ (designated XL1); $H_{6}$ DQMMLPWAVTLG $Y$ Y (XL2); $H_{6} W_{\text {WQHKIDLPYNGAG }} Y(X L 3) ;$ and their 17 residue non-His-tagged equivalents (XL4, XL5, and XL6). The HSA moiety of XL4- to XL6-HSA proteins was C-terminally His-tagged. All chimerae were efficiently secreted from transformed Pichia pastoris yeast except XL3$H S A$, and following nickel chelate affinity purification were found to be intact by amino acid sequencing, as was an $\mathrm{N}$-terminally His-tagged version of $\alpha_{2} \mathrm{AP}(13-42)-\mathrm{HSA}$. Of the proteins tested, XL5-HSA was cross-linked to biotin pentylamine (BPA) most rapidly by FXIlla, and was the most effective competitor of $\alpha_{2} A P$ crosslinking not only to BPA but also to plasma fibrin clots. In the mouse ferric chloride vena cava thrombosis model, radiolabeled XL5-HSA was retained in the clot to a greater extent than recombinant HSA. In the rabbit jugular vein stasis thrombosis model, XL5-HSA was also retained in the clot, in a urea-insensitive manner indicative of crosslinking to fibrin, to a greater extent than recombinant HSA.

Conclusions: Fusion protein XL5-HSA (DQMMLPWAVTLG $\mathrm{Y}_{4}-\mathrm{HSAH}_{6}$ ) was found to be more active as a substrate for FXIIla-mediated transamidation than seven other candidate fusion proteins in vitro. The improved stability and reactivity of this chimeric protein was further evidenced by its incorporation into in vivo clots formed in thrombosis models in both mice and rabbits.
\end{abstract}

\section{Background}

Recombinant serum albumins provide an attractive scaffold for the delivery of attached therapeutic peptides or proteins $[1,2]$. They are the most abundant proteins in the plasma of mammals, reaching concentrations of 40$80 \mathrm{mg} / \mathrm{mL}$ (0.6-1.0 mM) in humans [3]. They are slowly cleared plasma proteins $[3,4]$ whose longevity in the circulation derives from a well-characterized mechanism of recycling via the major histocompatibility complex-

\footnotetext{
* Correspondence: sheffiel@mcmaster.ca

'Department of Pathology and Molecular Medicine, McMaster University,

1200 Main Street West, Hamilton, Ontario, Canada

Full list of author information is available at the end of the article
}

related Fc receptor for immunoglobulin G (FcRn) [5-7]. Serum albumin is also unusual among plasma proteins in that it is not glycosylated [3], a property that simplifies its recombinant expression and production [8]. If candidate therapeutic peptides or proteins can be fused to albumin in a manner that allows them to express their endogenous activity, the resulting fusion protein often demonstrates improved pharmacokinetic and pharmacodynamic properties due to acquisition of albumin-like circulatory characteristics [1]. For these reasons, albumin has been fused to numerous proteins such as interferon [9], interleukin-2 [10], butrylcholinesterase [11], coagulation factors VII [12] and IX [13,14],

\section{() Biomed Central}


hirudin [15,16], and barbourin [17], as well as to smaller peptides [18].

In order to address unmet clinical needs in the area of thrombosis, the pathological formation of clots within intact blood vessels, our laboratory previously investigated novel recombinant proteins comprised of portions of $\alpha_{2}$-antiplasmin fused to the $\mathrm{N}$-terminus of human serum albumin [19]. $\alpha_{2}$ AP is cross-linked to fibrin clots by activated factor XIII (FXIIIa), where it promotes clot stability by inhibiting the fibrinolytic enzyme plasmin [20,21]. We [19] and others [22,23] have demonstrated that competing $\alpha_{2} \mathrm{AP}$-fibrin crosslinking results in fibrin clots that are more easily dissolved in vitro, suggesting potential applications of such competitors as adjuncts to thrombolytic therapy.

Previously, we attempted expression of three $\alpha_{2}$ APHSA fusion proteins in Pichia pastoris, a methylotropic yeast shown to produce recombinant HSA in high yield and with indistinguishable biophysical properties to its plasma-derived counterpart [24]. Our strategy was to retain the $\mathrm{N}$-terminal sites of $\alpha_{2} \mathrm{AP}$-fibrin crosslinking, especially Q14 [25], but to delete the Cterminal plasmin-binding and plasmin-trapping reactive centre loop of this serpin-type inhibitor. We sought to provide as native a protein environment as possible for the $\alpha_{2} \mathrm{AP}$ cross-linking motif by maximizing the portion of $\alpha_{2}$ AP fused to HSA. However, only a chimeric protein comprised of $\alpha_{2} \mathrm{AP}$ residues 13-42 fused to HSA was secreted by the yeast; the two longer fusions involving residues 13-73 and 13-109 were not stably expressed. Moreover, $\alpha_{2} \mathrm{AP}(13-42)-$ HSA was partially proteolyzed within its $\alpha_{2} \mathrm{AP}$ moiety. While we demonstrated that $\alpha_{2} \mathrm{AP}(13-42)$-HSA became a substrate of FXIIIa and competed for $\alpha_{2} \mathrm{AP}$ crosslinking to both small and macromolecular substrates, we could not demonstrate cross-linking to clots in vivo above background levels seen with recombinant HSA [19].

In the present study, we sought to improve the ability of HSA fusion proteins to compete with $\alpha_{2}$ AP for FXIIIa-mediated cross-linking. The $\alpha_{2} \mathrm{AP}$ moiety was reduced to 12 residues ( $\alpha_{2}$ AP 13-23 followed by Lys24Ala), to avoid previously observed sites of proteolysis by $P$. pastoris proteases, and compared to two 12residue artificial FXIIIa substrate peptides selected by phage display for high reactivity [26]. These motifs were expressed with or without $\mathrm{N}$-terminal His tags, to allow for purification of full length proteins away from partially proteolyzed products. We hypothesized that replacing $\alpha_{2}$ AP 13-42 with shorter, potentially more active FXIIIa substrate motifs would improve the stability of fibrin cross-linkable HSA proteins and improve in vivo clot retention.

\section{Methods}

\section{DNA Manipulations}

All oligonucleotides employed in this study were synthesized at MOBIX Lab, a McMaster University core facility. The sequences of all plasmids generated in this study were validated by DNA sequencing, also performed by MOBIX Lab, prior to use for protein expression. Standard molecular biological protocols for DNA restriction and ligation, plasmid mini-DNA preparation, purification of DNA from agarose gels, and transformation of $E$. coli Top10 (Invitrogen) to ampicillin resistance, were employed [19]. Three plasmids encoding fusion proteins XL4-, XL5-, and XL6HSA were first prepared, by analogous means. Synthetic oligonucleotides, whose sequences are shown in Table 1 , were first annealed by heating to $95^{\circ} \mathrm{C}$ and slow cooling to room temperature, in pairs, for each construct, respectively: ML-08-5116 and ML-08-5117; ML-08-5118 and ML-08-5119; and ML-08-5120 and ML-ML-08-5121. Annealed oligonucleotides were then separately ligated to the $6325 \mathrm{bp}$ XhoI-KpnI restriction digestion fragment of previously described plasmid pPICZ9ss- $\alpha_{2} \mathrm{AP}(13-73)-$ $\mathrm{HSAH}_{6}$ [19], replacing the $\alpha_{2} \mathrm{AP}(13-73)$ codons, forming plasmids pPICZ9ss-XL\#-HSAH ${ }_{6}$, where \# corresponds to 4,5 , or 6 , respectively. In order to construct XL-HSA constructs in which the His tag was not present on the C-terminus of the HSA moiety, an intermediate construct was prepared. A full-length preproHSA cDNA in pCDNA3.1 (Invitrogen), pC3ppHSA, was restricted with $\mathrm{XbaI}$ and ApaI, and the $804 \mathrm{bp}$ minor fragment was ligated to the major 5786 bp XbaI-ApaI fragment of pPICZ9ss- $\alpha_{2}$ AP (13-73)- $\mathrm{HSAH}_{6}$, yielding plasmid pPICZ9ss- $\alpha_{2} \mathrm{AP}(13-73)-$ HSA, in which the HSA open reading frame terminated without hexahistidine codons. The 5768 bp XhoI-KpnI restriction fragment of pPICZ9ss- $\alpha_{2} \mathrm{AP}$ (13-73)-HSA was then combined with the following pair-wise annealed oligonucleotides: ML-08-5104 and ML-08-5105; ML-085106 and ML-08-5107; and ML-08-5108 and ML-08-5109. This approach yielded plasmids pPICZ9ss-XL\#-HSAH ${ }_{6}$, where \# corresponds to 1,2 , or 3 , respectively. A final expression plasmid was constructed to reverse the orientation of the His tag of fusion protein $\alpha_{2} \mathrm{AP}(13-73)-\mathrm{HSAH}_{6}$ [19]. Plasmid pBAD- $\mathrm{H}_{6}-\alpha_{2} \mathrm{AP}$ [27] was PCR-amplified using oligonucleotides ML 09-3874 and 17225 [27], and the $125 \mathrm{bp}$ XhoI-KpnI restriction fragment of the resulting PCR product was inserted between the corresponding sites of pPICZ9ss- $\alpha_{2} \mathrm{AP}(13-73)-\mathrm{HSA}$ to yield pPICZ9ss$\mathrm{H}_{6} \alpha_{2} \mathrm{AP}(13-42)-\mathrm{HSA}$. Each completed plasmid listed above was used to transform Pichia pastoris strain X33 to Zeocin (Invitrogen) resistance as previously described [18].

\section{Fusion protein expression, purification, and characterization}

HSA fusion proteins were purified from media conditioned by transformed Pichia pastoris cells and induced 
Table 1 Oligonucleotides employed in this study

\begin{tabular}{|c|c|c|c|}
\hline \multicolumn{2}{|c|}{ Oligonucleotide } & \multirow{2}{*}{$\begin{array}{l}\text { Size } \\
(n t)\end{array}$} & \multirow[t]{2}{*}{ Purpose } \\
\hline Number & Sequence & & \\
\hline MI-08-5104 & $\begin{array}{l}\text { 5'-TCGAGAAAAG ACATCATCAT CATCATCATA ACCAGGAGCA GGTGTCCCCA } \\
\text { CTTACCCTCC TCGCTGGAGG TGGAGGGTAC-3' }\end{array}$ & 80 & Xhol-Kpnl sense strand for XL1-HSA \\
\hline ML-08-5105 & $\begin{array}{l}\text { 5'-CCTCCACCTC CAGCGAGGAG GGTAAGTGGG GACACCTGCT CCTGGTTATG } \\
\text { ATGATGATGA TGATGTCTIT TC-3' }\end{array}$ & 72 & Xhol-Kpnl antisense strand for XL1-HSA \\
\hline ML-08-5106 & $\begin{array}{l}\text { 5- TCGAGAAAAG ACATCATCAT CATCATCATG ATCAGATGAT GCTGCCATGG } \\
\text { CCAGCTGTGA CCCTGGGAGG CGGAGGGTAC -3’' }\end{array}$ & 80 & Xhol-Kpnl sense strand for XL2-HSA \\
\hline ML-08-5107 & $\begin{array}{l}\text { 5- CCTCCGCCTC CCAGGGTCAC AGCTGGCCAT GGCAGCATCA TCTGATCATG } \\
\text { ATGATGATGA TGATGTCTIT TC-3' }\end{array}$ & 72 & Xhol-Kpnl antisense strand for XL2-HSA \\
\hline ML-08-5108 & $\begin{array}{l}\text { 5'-TCGAGAAAAG ACATCATCAT CATCATCATT GGCAGCATAA AATCGATCTG } \\
\text { CCATACAATG GTGCAGGAGG CGGAGGGTAC-3' }\end{array}$ & 80 & Xhol-Kpnl sense strand for XL3-HSA \\
\hline ML-08-5109 & $\begin{array}{l}\text { 5'- CCTCCGCCTC CTGCACCATT GTATGGCAGA TCGATTTTAT GCTGCCAATG } \\
\text { ATGATGATGA TGATGTCTTT TC-3' }\end{array}$ & 72 & Xhol-Kpnl antisense strand for XL3-HSA \\
\hline ML-08-5116 & $\begin{array}{l}\text { 5'- TCGAGAAAAG AAACCAGGAG CAGGTGTCCC CACTTACCCT CCTCGCTGGA } \\
\text { GGTGGAGGGT AC -3' }\end{array}$ & 62 & Xhol-Kpnl sense strand for XL4-HSA \\
\hline ML-08-5117 & 5'- CCTCCACCTC CAGCGAGGAG GGTAAGTGGG GACACCTGCT CCTGGTTTCT TTTC-3'. & 54 & Xhol-Kpnl antisense strand for XL4-HSA \\
\hline ML-08-5118 & $\begin{array}{l}\text { 5'- TCGAGAAAAG AGATCAGATG ATGCTGCCAT GGCCAGCTGT GACCCTGGGA } \\
\text { GGCGGAGGGT AC -3' }\end{array}$ & 62 & Xhol-Kpnl sense strand for XL5-HSA \\
\hline ML-08-5119 & 5'- CCTCCGCCTC CCAGGGTCAC AGCTGGCCAT GGCAGCATCA TCTGATCTCT TITC -3' & 54 & Xhol-Kpnl antisense strand for XL5-HSA \\
\hline ML-08-5120 & $\begin{array}{l}\text { 5'-TCGAGAAAAG ATGGCAGCAT AAAATCGATC TGCCATACAA TGGTGCAGGA } \\
\text { GGCGGAGGGT AC-3' }\end{array}$ & 62 & Xhol-Kpnl sense strand for XL6-HSA \\
\hline ML-08-5121 & 5'-CCTCCGCCTC CTGCACCATT GTATGGCAGA TCGATTTAT GCTGCCATCT TTTC-3' & 54 & Xhol-Kpnl antisense strand for XL6-HSA \\
\hline ML-09-3874 & $\begin{array}{l}\text { 5'-ACGTGTCGAGA AAAGACATCA TCATCATCAT CATAACCAGG AGCAGGTGTC CCCAC- } \\
3^{\prime}\end{array}$ & 45 & $\begin{array}{l}\text { Upstream primer for PCR to assemble } \\
\mathrm{H}_{6} \mathrm{\alpha}_{2} \mathrm{AP}(13-42)-\mathrm{HSA}\end{array}$ \\
\hline ML 17225 & 5'-ACGTGGTACCG ACTCCTGGGG GACTCTTCAG-3' & 30 & $\begin{array}{l}\text { Downstream primer for PCR to assemble } \\
\mathrm{H}_{6} \alpha_{2} \mathrm{AP}(13-42)-\mathrm{HSA}\end{array}$ \\
\hline
\end{tabular}

with $0.5 \% \mathrm{vol} / \mathrm{vol}$ methanol, as previously described $[18,19,28]$, except that the methanol induction phase of protein production was extended to 96 hours. At that point, the conditioned media was neutralized and clarified by centrifugation [1], treated with protease inhibitors (5 mM benzamidine and $0.1 \mathrm{mM}$ phenylmethylsulfonyl fluoride), and purified using Ni-NTA agarose chromatography (Qiagen). Purified proteins were analyzed by SDSPAGE and immunoblotting using polyclonal affinity-purified goat anti-human $\alpha_{2}$ AP antibodies (Affinity Biologicals) and murine monoclonal anti-HSA antibodies (Genway Biotech). They were also characterized by automated Edman degradation at the Advanced Protein Technology Centre of the Hospital for Sick Children, Toronto, Canada.

Transglutamination assays with biotinylated pentylamine In order to quantify FXIIIa-catalyzed transglutamination of plasma-derived $\alpha_{2} \mathrm{AP}$ and recombinant HSA fusion proteins, a microtiter plate (Immulon $4 \mathrm{HBX}$, Thermo Scientific) protocol was developed. Test HSA-related proteins $(1.7 \mu \mathrm{M})$ were first incubated for varying times in Tris-buffered saline (50 mM Tris-Cl pH 7.5, $150 \mathrm{mM}$ $\mathrm{NaCl}$ ) containing $5 \mathrm{mM} \mathrm{CaCl}_{2}$ and $5 \mathrm{mM}$ biotinylated pentylamine (BPA; EZ-Link pentylamine-biotin, Pierce) supplemented with $20 \mathrm{nM}$ human FXIII (Enzyme Research Labs, ERL) and $1.0 \mathrm{IU} / \mathrm{mL}$ human thrombin (ERL). Reactions $(0.1 \mathrm{~mL})$ were stopped by addition of an equal volume of $20 \mathrm{mM}$ EDTA pH 8.00 and transferred to microtiter plates. Microtiter plates were prepared for use by coating with $2.5 \mu \mathrm{g} / \mathrm{mL}$ mouse antiHSA monoclonal antibody (Genway) in $50 \mathrm{mM}$ sodium carbonate $\mathrm{pH} 9.6$ overnight at $4^{\circ} \mathrm{C}$. All other incubations were at room temperature. All washes were performed with Tris-buffered saline supplemented with $0.05 \%$ (vol/ vol) Tween 20 (TBST), and repeated three times. AntiHSA-coated plates were washed and then blocked for one hour in TBST, then washed again. Following transfer of the stopped transglutamination reaction mixtures to the plate, it was incubated with shaking for one hour and washed, prior to reaction of captured proteins with a 1:2500 dilution of alkaline phosphatase-conjugated streptavidin (Jackson Labs) in TBST for one hour. Following a final wash step, colour was developed by addition of $1.0 \mathrm{mg} / \mathrm{ml} p$-nitrophenyl phosphate disodium salt (PNPP) in diethanolamine buffer (1.02 M diethanolamine $\mathrm{pH}$ 9.8) (Thermo Scientific) and absorbance was quantified on an ELx808 plate reader (BioTek Instruments) at $405 \mathrm{~nm}$ for up to 15 minutes. In some reactions, the protocol was modified to measure 
transglutamination of $\alpha_{2} \mathrm{AP}$ by substituting anti- $\alpha_{2} \mathrm{AP}$ antibodies for anti-HSA antibodies, and purified human plasma-derived $\alpha_{2} \mathrm{AP}$ (ERL) for HSA-related proteins.

\section{Transglutamination of fibrin(ogen)}

FXIIIa-catalyzed transglutamination of the natural substrate fibrinogen was assessed using SDS-PAGE and immunoblotting of cross-linking reactions as previously described [19]. Briefly, 100 nM FXIII was first activated to FXIIIa by reaction with $5.0 \mathrm{IU} / \mathrm{ml}$ thrombin for 5 minutes at $37^{\circ} \mathrm{C}$; thrombin was then inactivated using Phe-Pro-Arg chloromethylketone to $10 \mu \mathrm{M}$ final concentration, to prevent clotting on addition to fibrinogen. The resulting FXIIIa $(50 \mathrm{nM})$ was reacted with $6.0 \mu \mathrm{M}$ human fibrinogen (specifically depleted of plasminogen, von Willebrand factor, and fibronectin, ERL), and 1.0 $\mu \mathrm{M}$ substrate proteins in TBS containing $10 \mathrm{mM} \mathrm{CaCl}_{2}$.

Reactions were stopped by addition of SDS and analyzed on $8 \%$ SDS-polyacrylamide gels under reducing conditions, with immunoblotting and chemiluminescent development of antibody-decorated blots, as described [19].

\section{In vitro clot lysis}

As previously described [19], the formation and dissolution of human plasma clots was followed by recording changes in turbidity, using an ELx808 plate reader (BioTek Instruments) set to take absorbance readings at 340 nm every 30 seconds for 4 hours, and quantified as the area under the curve.

\section{Retention of iodinated proteins in mouse vena cava treated with ferric chloride}

Purified human fibrinogen (Sigma), human $\alpha_{2}$ AP (ERL), or XL5-HSA recombinant proteins were iodinated using the Iodogen method as described by the manufacturer (Pierce), using either sodium ${ }^{125} \mathrm{I}$ or ${ }^{131} \mathrm{I}$. Unincorporated radioactivity was removed by exhaustive dialysis versus phosphate-buffered saline. Specific activities of labelling exceeded $1 \times 10^{9} \mathrm{cpm} / \mathrm{mg}$. Radioiodinated proteins were then tested in the mouse ferric chloride vena cava thrombosis model, modified from [29,30]. CD-1 mice were anaesthetized using gaseous anaesthesia (3\% isofluorane) at all times during this procedure, and a heating pad was employed to ensure maintenance of normal body temperature. A mid-line incision was made, first through the skin and secondly through the muscle layer. Viscera were gently displaced and haemostatic clamps employed to keep the incision open. At this time radioiodinated proteins $\left(5 \times 10^{6} \mathrm{cpm}\right.$ in $0.1 \mathrm{ml}$ sterile saline) were injected via the tail vein. The vena cava was then exposed and a $2 \times 4 \mathrm{~mm}$ piece of Whatman paper soaked in $10 \%$ (w/vol) ferric chloride was applied. The viscera were covered with gauze soaked in warm saline during this time. The time from radioactive protein injection to application of ferric chloride was fixed at 5 minutes. Three minutes after its application, the filter paper was removed and viscera replaced. Thirty minutes later, the vena cava was re-exposed, the vessel was excised, and the clot was transferred to a tared tube for weighing, and then subjected to $\gamma$ counting using either an Auto Gamma 5530 Minaxi $\gamma$ counter (Perkin Elmer) or a Cobra II $\gamma$ counter (Packard) to quantify incorporated radioactivity.

\section{Retention of iodinated proteins in rabbit jugular vein thrombi}

New Zealand White rabbits were subjected to a modified Wessler procedure [31] as previously described by this laboratory [19]. Briefly, animals were initially anesthetized with $100 \mathrm{mg}$ of ketamine, then maintained in the anesthetized state with $1.5 \%$ isoflurane. They were then cannulated via the carotid artery and the jugular veins isolated. One $\mathrm{ml}$ of whole blood was freshly drawn and anticoagulated with $1 / 9^{\text {th }}$ volume of $3.8 \% \mathrm{w} / \mathrm{vol}$ sodium citrate. Two centimeter long sections of the right and left jugular veins were isolated, emptied of blood, and isolated using bulldog clamps. Clotting of the anticoagulated, autologous whole blood was initiated by combining it with warm $\left(37^{\circ}\right)$ human thromboplastin reagent Thromborel S (Dade Behring) in a 1:4 (vol:vol) ratio, supplementing it to $3.3 \times 10^{6} \mathrm{cpm} / \mathrm{ml}^{131} \mathrm{I}$ - fibrinogen and ${ }^{125}$ I-recombinant protein, and re-introducing $0.15 \mathrm{ml}$ of the clotting blood into the isolated segments. This was done for both isolated jugular veins and blood flow was held in stasis for 30 minutes, at which time the clamps were removed, and blood flow restored. Clots were recovered 60 minutes later, following jugular vein opening by incision, and removed, weighed, and $\gamma$ counted as described above for murine clots. In some experiments clots were extracted overnight in $5.0 \mathrm{M}$ urea, microcentrifuged, and the supernatant removed prior to re-counting. The proportion of urea-stable protein incorporation was then calculated, adjusted for radioactive decay between the recorded times of the first and second $\gamma$-count. All animal experiments were carried out under the terms of an approved Animal Utilization Protocol reviewed, approved, and monitored by the Animal Research Ethics Board of the Faculty of Health Sciences, McMaster University.

\section{Statistical analysis}

Statistical tests were performed using GraphPad Instat version 4 (GraphPad Software). Multiple comparisons used one-way parametric analysis of variation (ANOVA) with Tukey-Kramer post-tests where data were normally distributed, and nonparametic ANOVA with Dunn's post-tests where they were not. 


\section{Results}

Expression and characterization of fusion proteins

Media conditioned by Pichia pastoris cultures transformed with expression plasmids encoding fusion proteins XL(1-6)-HSA (see Figure 1) were first screened for recombinant expression of HSA-related polypeptides by gel analysis. As shown in Figure 2A, although there were some differences in the time course of expression, five of six of the yeast cell lines secreted a major methanol-dependent polypeptide of the expected size of the HSA fusion proteins, of 70-80 kDa. The exception was the cell line programmed to express XL3-HSA, which secreted no detectable methanol-dependent polypeptides.

The five putative HSA fusion proteins were purified from conditioned media induced with methanol for 96 hours, using nickel chelate affinity chromatography, and reacted both with anti-HSA and anti-hexahistidine antibodies, as shown in Figure 2B. The same properties were observed for $\mathrm{H}_{6} \alpha_{2} \mathrm{AP}(13-42)$-HSA and previously described $\alpha_{2} \mathrm{AP}(13-42)$-HSA [19] (Figure 2). Similar results were obtained when an additional two

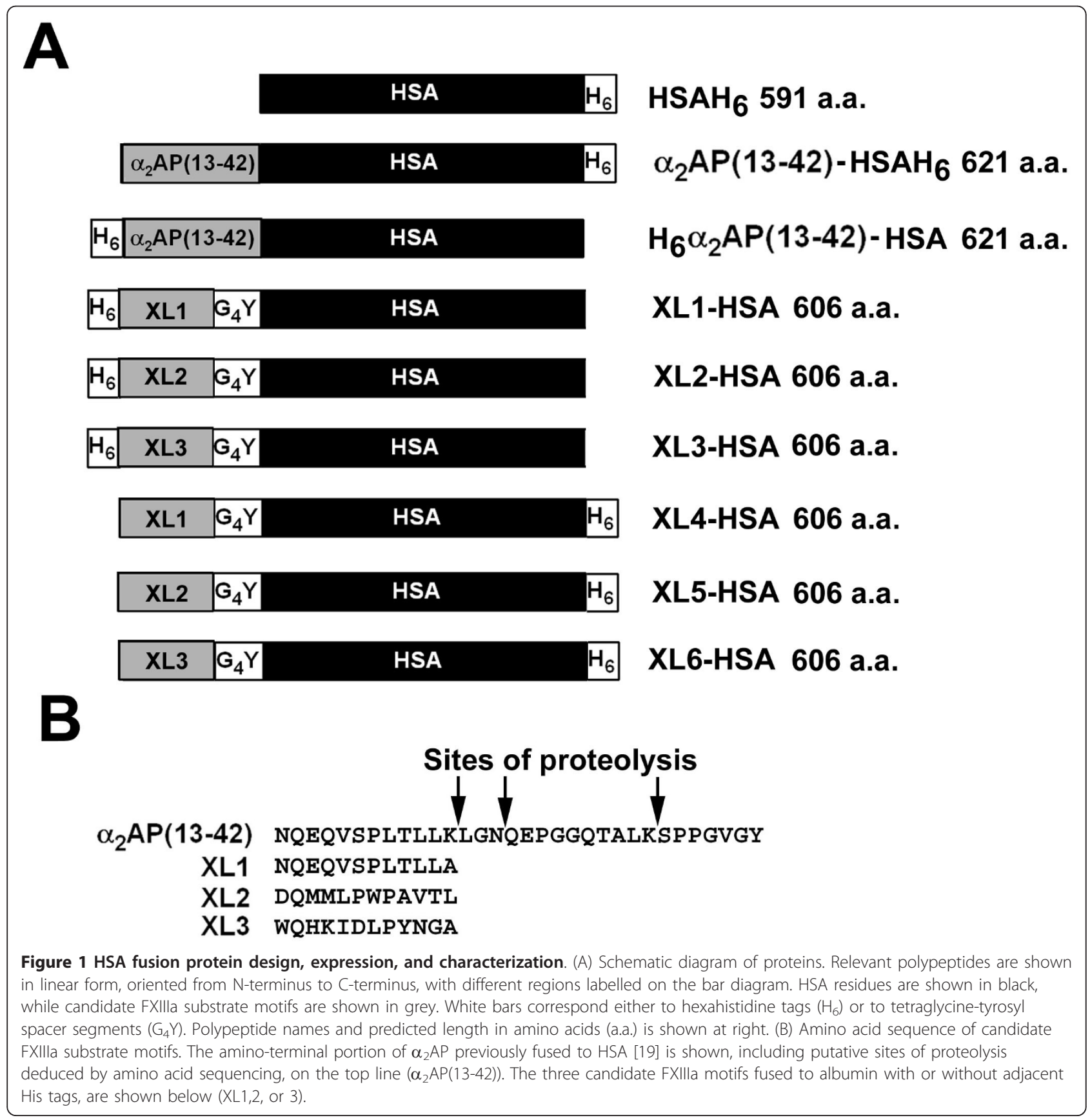



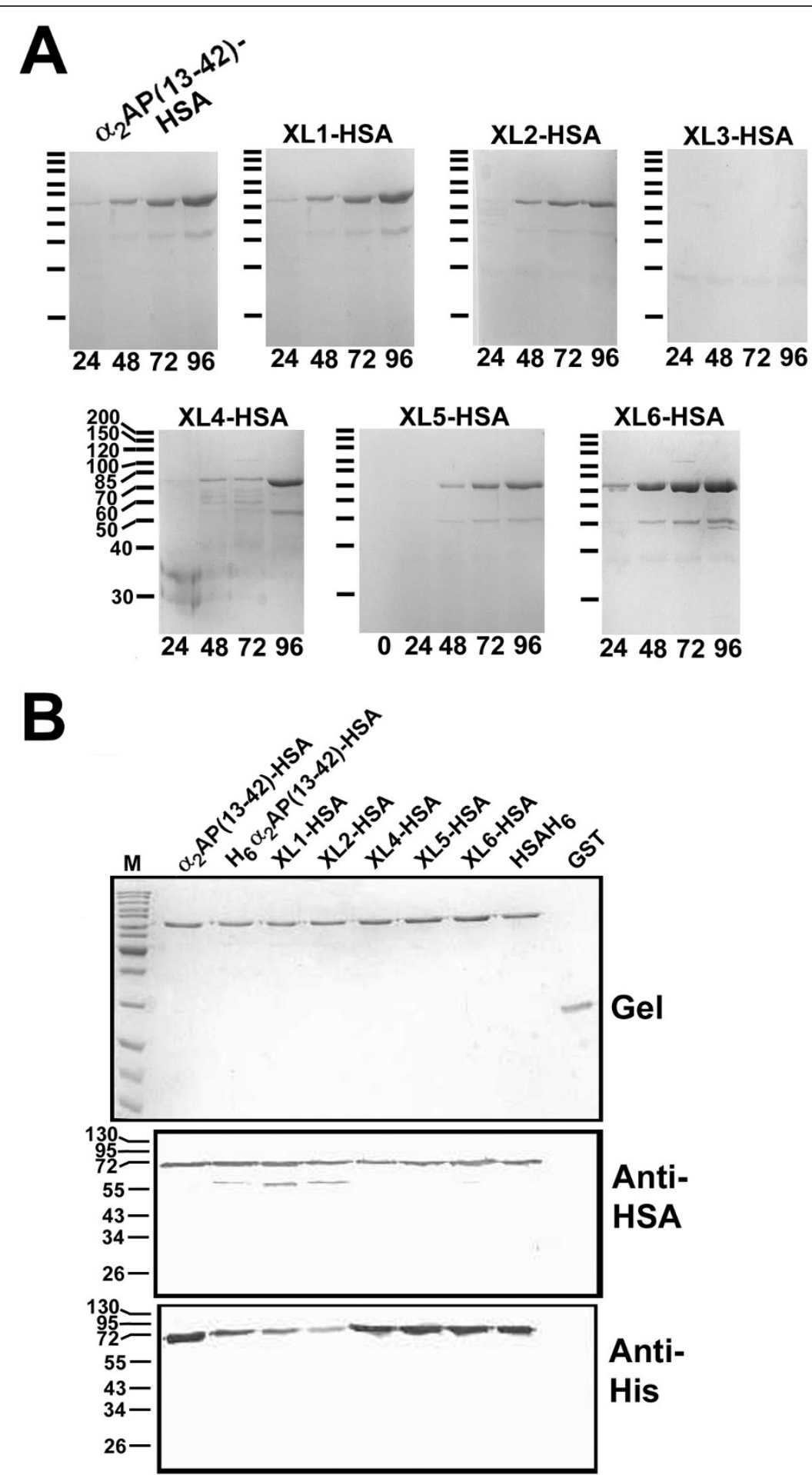

Figure 2 Expression, purification and characterization of HSA-related recombinant proteins. (A) Electrophoresis of conditioned media from P. pastoris transformed with different expression plasmids. Conditioned media samples taken 24, 48, 72, or 96 hours after the start of methanol induction are shown on 10\% reducing SDS-polyacrylamide gels stained with Coomassie Blue. The protein product encoded by the expression plasmid is shown above each gel. The position of molecular mass markers $(200,150,120, .100,85,70,60,50,40$, and $30 \mathrm{kDa})$ is shown to the left of each panel and labelled (XL4-HSA) in one instance as an example. (B) Upper panel, gel profile of purified recombinant proteins on 10\% SDS-polyacrylamide gels electrophoresed under reducing conditions and stained with Coomassie Blue. Proteins (400 ng) are identified above each lane as in Figure 1A, plus GST (E.coli-expressed glutathione sulfotransferase); M, molecular mass markers identical to those used in Figure 1A. Middle and lower panel, replicate gels differing only in the amounts of protein loaded per lane, to avoid overloading with antibodies of different affinity, were immunoblotted and probed with Anti-HSA antibodies (middle pane, 100 ng/lane) or anti-hexahistidine antibodies (lower panel, Anti-His, 500 ng/lane). 
independent $P$. pastoris Zeocin-resistant cell lines were examined, in addition to the ones shown in Figure 2 (data not shown).

Because the minor, 2-4 $\mathrm{kDa}$ difference between the shortest $\left(\mathrm{HSAH}_{6}\right)$ and longest $\left(\mathrm{H}_{6} \mathrm{\alpha}_{2} \mathrm{AP}(13-42)-\mathrm{HSA}\right)$ putative expression proteins was not resolvable on the gel system we employed, we sought independent confirmation of the identity and integrity of the expressed protein products by amino acid sequencing. For XL(46)-HSA, a single N-terminal sequence was detected by Edman degradation: NQEQVS; DQMMLP; and WQHKID, respectively. For XL1-HSA and XL2-HSA, Edman degradation showed intact hexahistidine aminotermini. For $\mathrm{H}_{6} \alpha_{2} \mathrm{AP}(13-42)-\mathrm{HSA}$, two sequences were detected: the major sequence arising from the expected hexahistidine tag, and the other a mixture of amino acids suggestive of a similar pattern of partial proteolysis we previously reported for $\alpha_{2} \mathrm{AP}(13-42)$-HSA [19]. In that regard, batches of the latter protein were prepared using 96 hours of methanol induction, as employed for all other proteins in this study, for consistency and for comparative purposes. Edman degradation showed a mixture of termini similar to those previously observed from cultures induced for lesser periods of time [19]. These included termini commencing with Leu23 (LKLGNQ), Leu25 (LGNQEP), and Ser38 (SPPGVC) but no detectable full-length product. Three separate batches of such protein preparations returned similar results (data not shown).

While the amino acid sequencing results showed that positioning of a hexahistidine tag on the N-terminus of $\alpha_{2} \mathrm{AP}(13-42)-\mathrm{HSA}$ improved the integrity of the resulting purified protein product, the yield was reduced from 40-50 mg/l for AP(13-42)-HSA to 5-6 mg/l for $\mathrm{H}_{6} \alpha_{2} \mathrm{AP}$ (13-42)-HSA. Yields for the purified XL-HSA proteins varied from 10-12 mg/l (XL1- and XL2-HSA) to 20-35 $\mathrm{mg} / \mathrm{l}$ ( XL4- and XL5-HSA) to 80-85 mg/l (XL6-HSA).

\section{Characterization of recombinant fusion proteins as fXIIla substrates for cross-linking to lysine donors}

Having demonstrated that all recombinant fusion proteins with the exception of XL3-HSA had been produced, we next asked whether the addition of the candidate FXIIIa sequences had actually converted the proteins into substrates for cross-linking by FXIIIa. Cross-linking reactions were performed in solution, using the chemical amine donor biotinylated pentylamine, and reaction products were captured using antibodies immobilized on microtiter plate walls and quantified colorimetrically using alkaline-phosphataselinked streptavidin. As shown in Figure 3A, while there was evidence of some cross-linking for all proteins tested, the highest levels were observed for fusion proteins XL5-HSA and XL2-HSA, in that order. While the

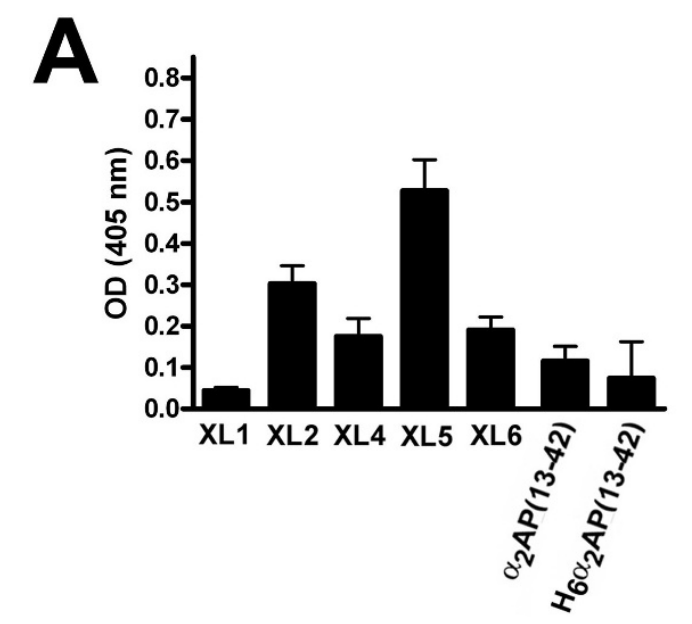

B

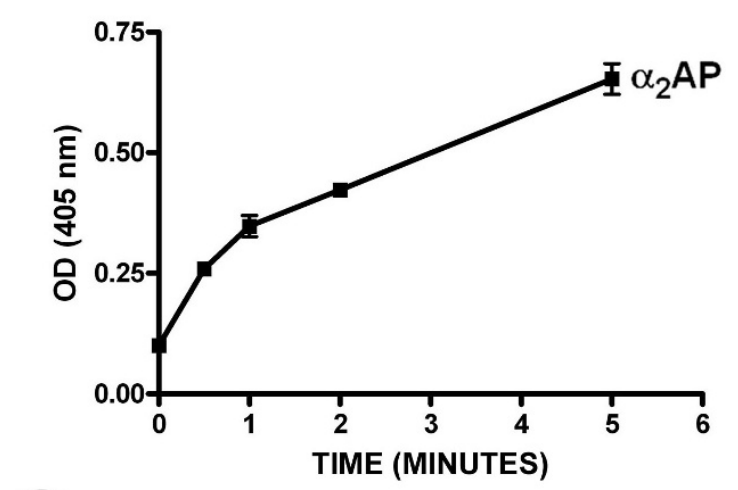

。

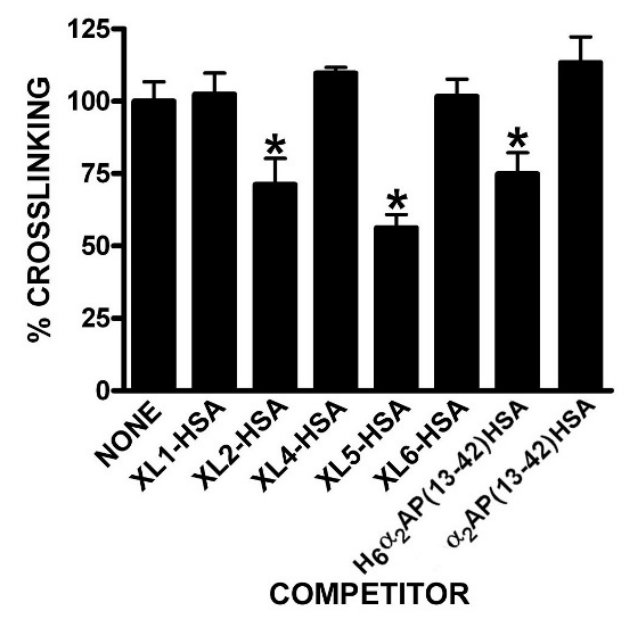

Figure 3 FXIIla-mediated cross-linking of recombinant proteins and plasma-derived $\alpha_{2} \mathrm{AP}$ to biotinylated pentylamine. Panel A shows transglutamination reactions, in which 20 nM FXIlla crosslinked $5 \mathrm{mM}$ BPA to $1.7 \mu \mathrm{M}$ HSA fusion proteins (identified below the $\times$ axis), were stopped after 2.5 minutes and the relative BPA incorporation was quantified using anti-HSA capture and alkaline phosphatase-conjugated streptavidin detection as outlined in "Methods". Colour generation was quantified as the optical density 
at $405 \mathrm{~nm}(\mathrm{OD}(405 \mathrm{~nm}))$. The mean \pm standard deviation (SD) of 6 determinations is shown, with background (reactions lacking FXIIla) subtracted. Panel B shows a time course of FXIlla-mediated crosslinking of BPA to $1.7 \mu M \alpha_{2} A P$, using the same conditions as employed in Panel A except that anti- $\alpha_{2} A P$ antibodies were used to capture biotinylated $\alpha_{2} \mathrm{AP}$ after reaction termination at various time points. The mean \pm the standard deviation (SD) of 3 determinations is shown, with background (reactions lacking FXIIlla) subtracted. Panel $C$ shows BPA- $\alpha_{2} A P$ crosslinking reactions of 5 minutes' duration, as shown in panel $B$, except that competitor proteins identified on the $\times$ axis were included at $12 \mu \mathrm{M}$. The mean \pm the SD of 5-14 determinations is shown, with background (reactions lacking FXIIla) subtracted.

results shown in Figure 3A were limited to initial (2.5 minute) reactions, by five minutes the cross-linking of XL2-HSA and XL5-HSA had become comparable (data not shown).

Similar results were obtained when HSA fusion proteins were employed as competitors of the FXIIIadependent transfer of biotin from BPA to $\alpha_{2} \mathrm{AP}$, which exhibited time-dependent crosslinking on the time scale employed (see Figure 3B). As shown in Figure 3C, of seven proteins tested using a seven-fold excess of competitor over $\alpha_{2}$ AP, only XL5-HSA, XL2-HSA, and $\mathrm{H}_{6} \alpha_{2} \mathrm{AP}(13-42)$-HSA significantly reduced cross-linking of $\alpha_{2} \mathrm{AP}$; the relative efficacy of the proteins was in the order listed. To minimize the possibility that reactivity with BPA was an artefact that did not accurately predict reactivity with macromolecular donors, the ability of XL5-HSA to be cross-linked to fibrinogen was tested. As shown in Figure 4, XL5-HSA and $\alpha_{2}$ AP exhibited similar kinetics in forming high molecular weight products with fibrinogen that were dependent on added FXIIIa, although the fact that different antibodies, with potentially different binding efficiency, had to be employed limited the comparison to a qualitative assessment. A similar pattern was observed for both proteins in that three higher molecular weight bands of $140 \mathrm{kDa}$ and greater formed in a factor XIIIa- and fibrinogendependent manner; with respect to plasma-derived $\alpha_{2} \mathrm{AP}$, these bands have been suggested to represent $\alpha_{2} \mathrm{AP}$-fibrinogen A $\alpha$ chain, $\alpha_{2} \mathrm{AP}$-fibrinogen A $\alpha$ dimer, and $\alpha_{2} \mathrm{AP}$-fibrinogen A $\alpha$ polymers [32].

\section{Comparison of fusion proteins as competitors of $\alpha_{2}$ AP- mediated in vitro clot protection}

$\alpha_{2}$ AP attenuates the ability of tPA to lyse fibrin clots by inhibiting plasmin generated by tPA-mediated activation of plasminogen. This property can be demonstrated in vitro using $\alpha_{2} \mathrm{AP}$-deficient plasma. As shown in Figure $5 \mathrm{~A}$, clots formed in the absence of $\mathrm{tPA}$ and $\alpha_{2} \mathrm{AP}$ were stable for $>4$ hours, whereas the addition of tPA lead to complete lysis within 60 minutes. Restoration of $\alpha_{2} \mathrm{AP}$ to its physiological concentration of $1 \mu \mathrm{M}$ restored approximately $70 \%$ of the area under the turbidity curve. The ability of the HSA-related fusion proteins to compete for the $\alpha_{2} \mathrm{AP}$-mediated lysis attenuation was tested by addition of $20 \mu \mathrm{M}$ fusion proteins. Although at this excess, some changes in the shape of the turbidity plot in the presence of fusion protein and the absence of fusion protein could be noted (Figure 5A), the area under the curve (AUC) of the turbidity curve did not differ from baseline, as exemplified for XL5HSA and XL6-HSA in Figure 5B. XL5-HSA significantly reduced the $\alpha_{2} \mathrm{AP}$-mediated attenuation of clot lysis,

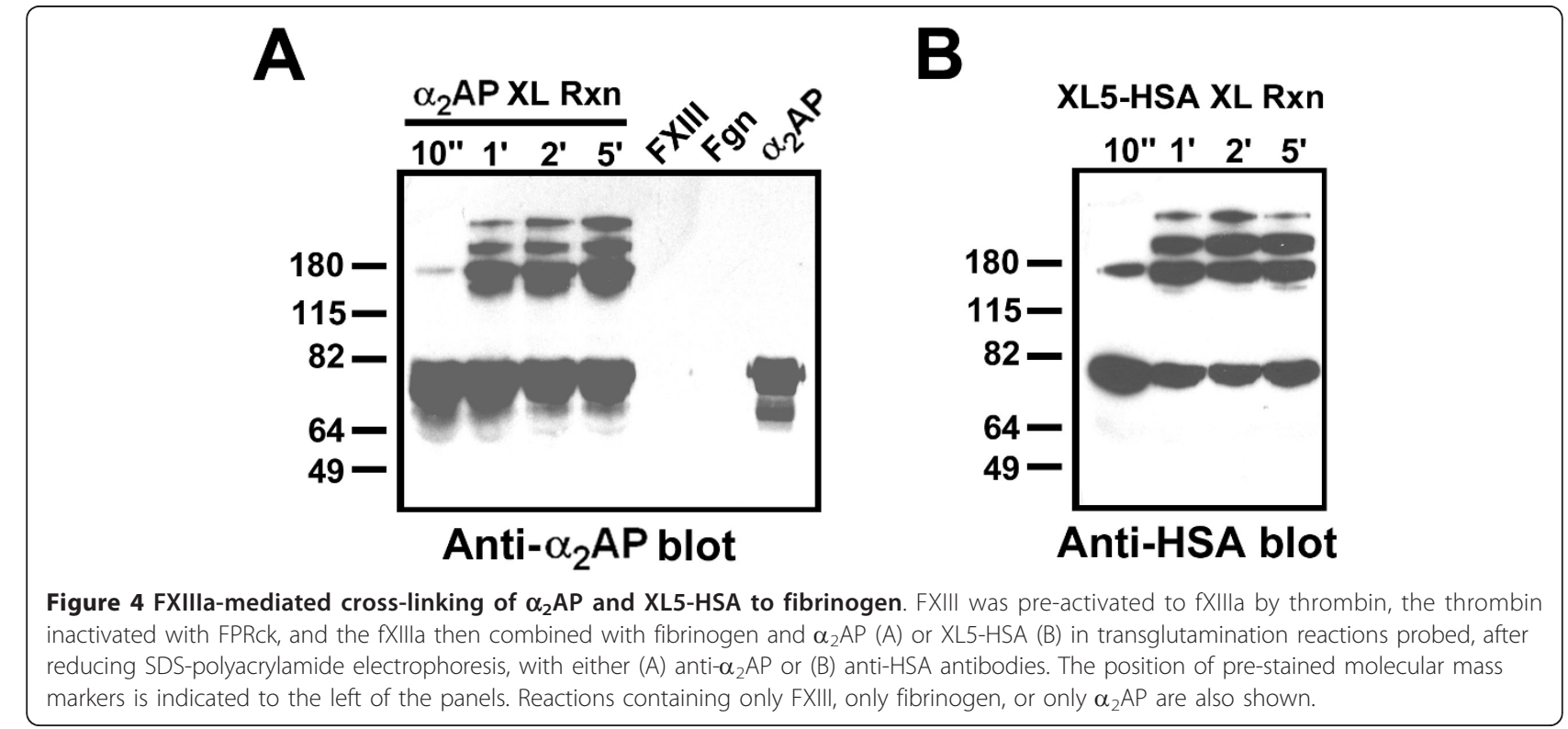

B 


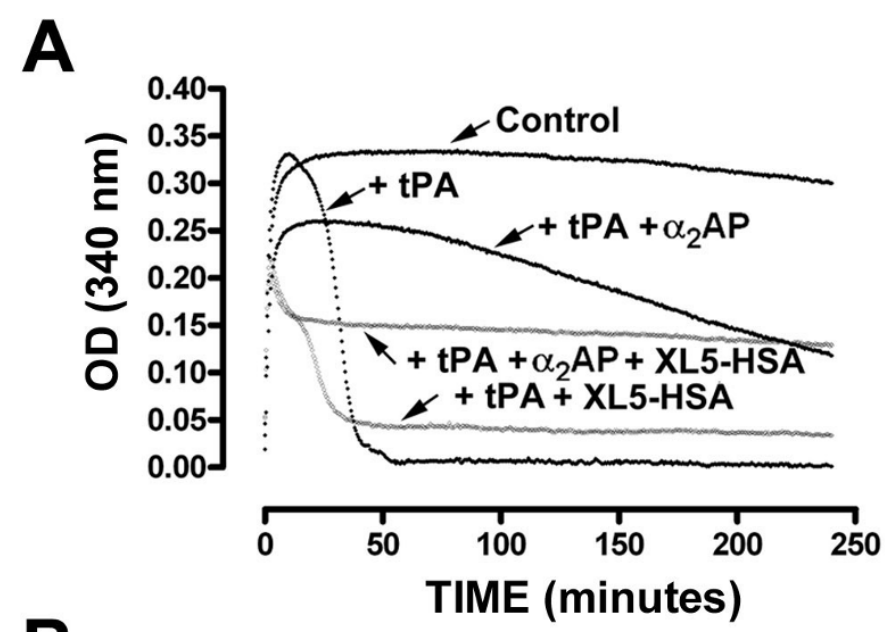

B

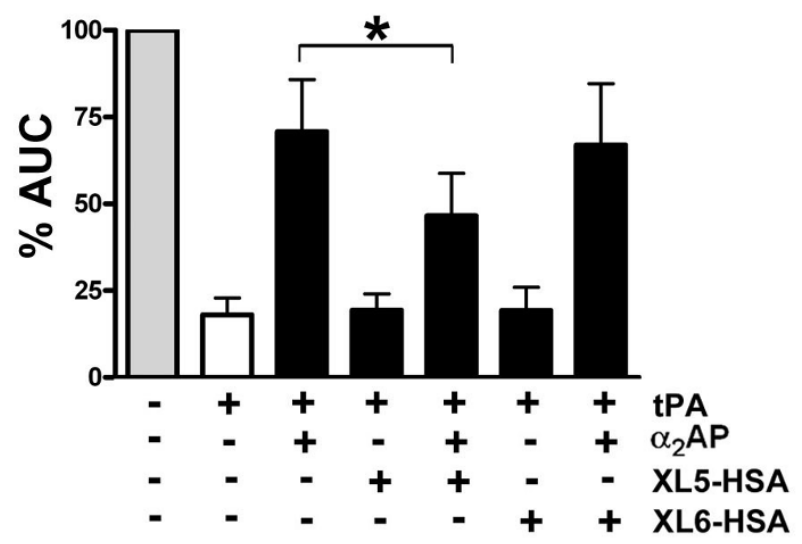

C

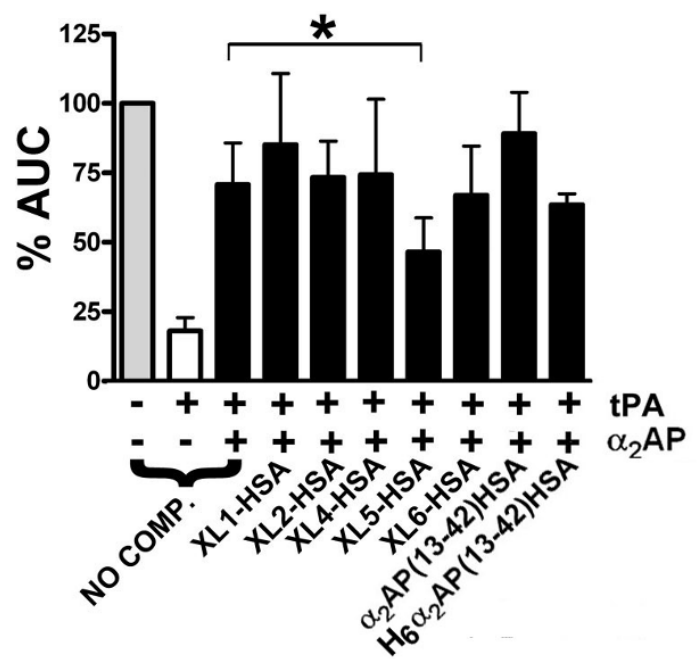

Figure 5 Effects of $\alpha_{2} \mathrm{AP}$ and recombinant HSA-related proteins on plasma clot formation and lysis. Clot formation and lysis were followed by monitoring turbidity (absorbance at $340 \mathrm{~nm}$ ) every 30 seconds for 4 hours using a plate reader, of clots formed using diluted $\alpha_{2}$ APdeficient plasma, recalcified with $5 \mathrm{mM} \mathrm{CaCl}$ and supplemented with both $5 \mathrm{nM}$ thrombin and $0.125 \mathrm{nM} \mathrm{tPA}$, and taking the area under the turbidity versus time curve (AUC). Reactions were carried out with or without addition of $1 \mu \mathrm{M} \alpha_{2} \mathrm{AP}$ and/or $20 \mu \mathrm{M}$ fusion protein. (A) shows results of a single representative experiment. (B) shows quantification of turbidity plots for reactions similar to those shown in $A$, in the presence or absence of XL5-HSA or XL6-HSA competitor proteins; reaction components are indicated (+ or -) below the graph. The mean \pm SD of 5-14 determinations is shown. AUC values were normalized, taking the no tPA, no $\alpha_{2}$ AP condition as $100 \%$ (grey bar); white (open) bars correspond to tPA only condition. (C) shows similar results to panel B for additional competitor proteins identified below the graph. As in panel B, the mean \pm SD of 5-14 determinations is shown. 
shifting the AUC from $70.8 \pm 14 \%$ of maximal clotting to $40.5 \pm 2.9 \%$ (Figure $5 \mathrm{~B}$ ); in contrast XL6-HSA did not compete for the $\alpha_{2}$ AP effect. Extension of these comparisons to the complete set of recombinant fusion proteins showed that only XL5-HSA and $\mathrm{H}_{6} \mathrm{\alpha}_{2} \mathrm{AP}(13-$ 42)-HSA, under the conditions employed, reduced the $\alpha_{2}$ AP effect, and that only the XL5-HSA reduction was statistically significant.

\section{Fusion protein XL5-HSA is retained in experimental thrombi in mice and rabbits}

Having obtained several lines of evidence that fusion protein XL5-HSA was the most effective FXIIIa substrate of the recombinant proteins tested, we next asked whether, like $\alpha_{2} \mathrm{AP}$, it was capable of being retained within whole blood clots in vivo. As shown in Figure $6 \mathrm{~A}$, when equal doses of radiolabeled $\alpha_{2} \mathrm{AP}$, XL5-HSA, and $\mathrm{HSAH}_{6}$ were injected into mice that formed experimental thrombi in the vena cava due to ferric chloride administration, both $\alpha_{2} \mathrm{AP}$ and XL5-HSA were retained within clots to a significantly greater extent than $\mathrm{HSAH}_{6}$. The retention of $\alpha_{2} \mathrm{AP}$ on a clot weight basis, was also significantly greater than that of XL5-HSA.

Similar results were obtained using a larger, rabbit experimental model in which the radiolabeled proteins were introduced, with a coagulation activator, into a whole blood segment within the isolated rabbit jugular vein. As shown in Figure 6B, the three proteins were found to become incorporated into the clot with the same relative efficacy as in the murine model; both $\alpha_{2}$ AP and XL5-HSA were incorporated to a greater extent than $\mathrm{HSAH}_{6}$. However, in common with the murine results, the XL5-HSA tracer incorporation was significantly less than that of $\alpha_{2} \mathrm{AP}$.

\section{Fusion protein XL5-HSA is retained in a urea-sensitive manner in experimental thrombi in rabbits}

In the larger animal model, the rabbit, the greater physical size of the clot permitted its manipulation, unlike with the much smaller murine thrombi. Prolonged stasis and the direct introduction of tissue factor activator into the isolated vessel strongly favoured thrombus formation in the rabbit model, as compared to the localized application of indirectly procoagulant ferric chloride to a localized area of a much smaller vessel in the mouse. Accordingly, clot weights from rabbits ranged from 21.4 to $54.1 \mathrm{mg}$ versus 5.1 to $11.4 \mathrm{mg}$ in mice. This greater size permitted clot extraction in $5.0 \mathrm{M}$ urea and determination of the fraction of clot-bound radioactivity that was insensitive to urea, a hallmark of cross-linked protein clot incorporation. In these experiments, the three ${ }^{125}$ I-labeled proteins were each separately co-administered with ${ }^{131}$ I-labeled fibrinogen. As shown in Figure $7 \mathrm{~A}$, approximately $50 \%$ of injected fibrinogen was clot- associated in a urea-insensitive manner; there were no differences between treatment groups, as expected because tracer-level doses of the recombinant proteins were employed. While significantly greater amounts of $\alpha_{2}$ AP remained clot-bound after urea extraction than XL5-HSA $(15.8 \pm 2.8 \%$ of injected dose versus $7.52 \pm$ $1.7 \%$ ) (Figure 7B), this represented 15- and 7.5-fold greater urea-insensitive retention than for $\mathrm{HSAH}_{6}(1.00$ $\pm 0.43 \%)$.

\section{Discussion}

In this study, we sought to increase the stability and activity of HSA fusion proteins containing short Nterminal extensions that are substrates for transglutamination by FXIIIa. Our long-term goal was to produce well-tolerated therapeutic proteins for injection, with the long circulatory half-life of albumin, and the ability to compete the cross-linking of $\alpha_{2} \mathrm{AP}$ to fibrin in thrombi. Replacing active $\alpha_{2} \mathrm{AP}$ in the clot with a protein incapable of inhibiting plasmin could render pathological clots easier to dissolve. Others have suggested that chemically or mutationally inactivated $\alpha_{2} \mathrm{AP}$ could serve this purpose $[22,23]$, while we have focused on the albumin fusion strategy [19], due to the ease of large-scale production of recombinant albumin [8]. In this study, we built chimeric albumin fusion proteins modelled on $\alpha_{2} \mathrm{AP}(13-42)-\mathrm{HSA}$, seeking to eliminate the partial proteolysis of this prototype, but retain and enhance its ability to be cross-linked by FXIIIa. Our approaches included shortening the natural $\alpha_{2}$ AP-derived crosslinking site, replacing it with either of two FXIIIa highly active substrate sequences identified by phage display, and capping all three novel chimerae with hexahistidine tags.

Substituting the sequence DQMMLPWPAVTL for $\alpha_{2} \mathrm{AP}(13-42)$, in fusion protein XL5-HSA, was found to be the most effective approach. This sequence had been reported to be a highly favourable substrate for FXIIIamediated transglutamination, when expressed fused to a phage coat protein or to glutathione sulfotransferase (GST) (designated F11 in [26]). When expressed fused to HSA, it yielded the candidate protein most rapidly and efficiently cross-linked to BPA, and the most effective competitor of $\alpha_{2} \mathrm{AP}$ crosslinking, both with small substrates and in competition of $\alpha_{2}$ AP's in vitro antifibrinolytic effect. The molecular context of the fusion partner was relevant, since sequence WQHKIDLPYNGA, identical to sequence F28 in [26], except for substitution of protease-susceptible $\mathrm{R}$ for $\mathrm{P}$ at position 8 , appeared to be much less active in fusion protein XL6-HSA than in the GST context. Similarly, $\alpha_{2}$ AP(1323)K24A, although shown to be effectively crosslinked by FXIIIa as $\alpha_{2} \mathrm{AP}(13-23)$ or $\alpha_{2} \mathrm{AP}(13-24)$ free peptides [33-35], was ineffective at competing $\alpha_{2} \mathrm{AP}$ crosslinking 

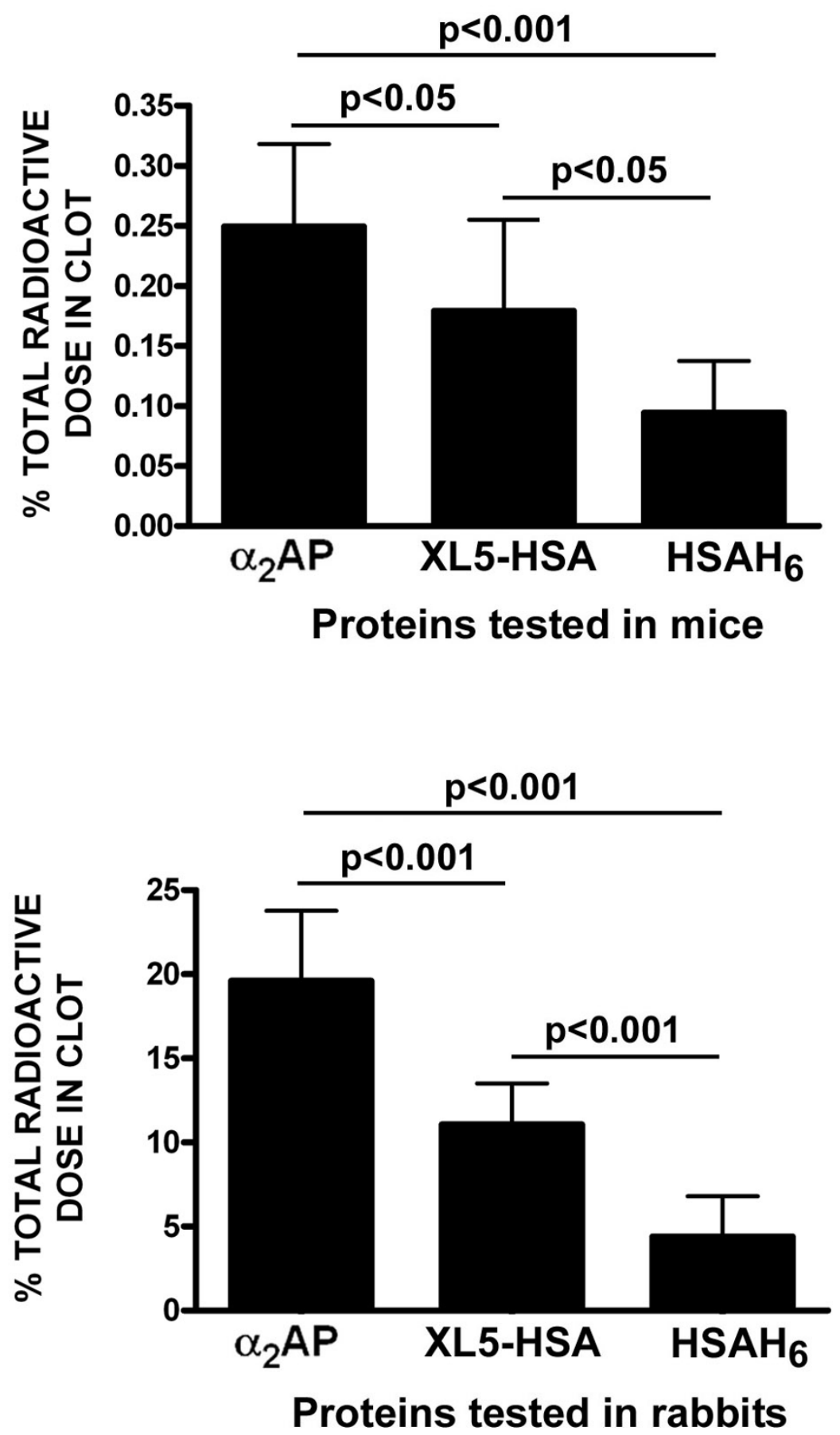

Figure 6 Retention of radiolabeled proteins in experimental thrombi formed in mice or rabbits. (A) The radioactivity remaining in clots induced by surgical, topical application of $10 \%$ ferric chloride to the vena cava of anesthetized mice is shown, as a fraction of the total

radioactive protein dose injected, divided by the weight of the clot. Injected radiolabeled proteins are identified on the $\times$ axis. The mean \pm SD of 12 determinations is shown. (B) The radioactivity remaining in rabbit jugular vein clots formed in clamped-off vessels in situ for 30 minutes in the anesthetized animal, then exposed to circulating blood for 60 minutes, prior to clot recovery and $\gamma$-counting is shown, expressed as in Figure 6A. The extent $(p<0.001, p<0.05)$ of statistical significance is shown for the data sets linked by horizontal lines. 

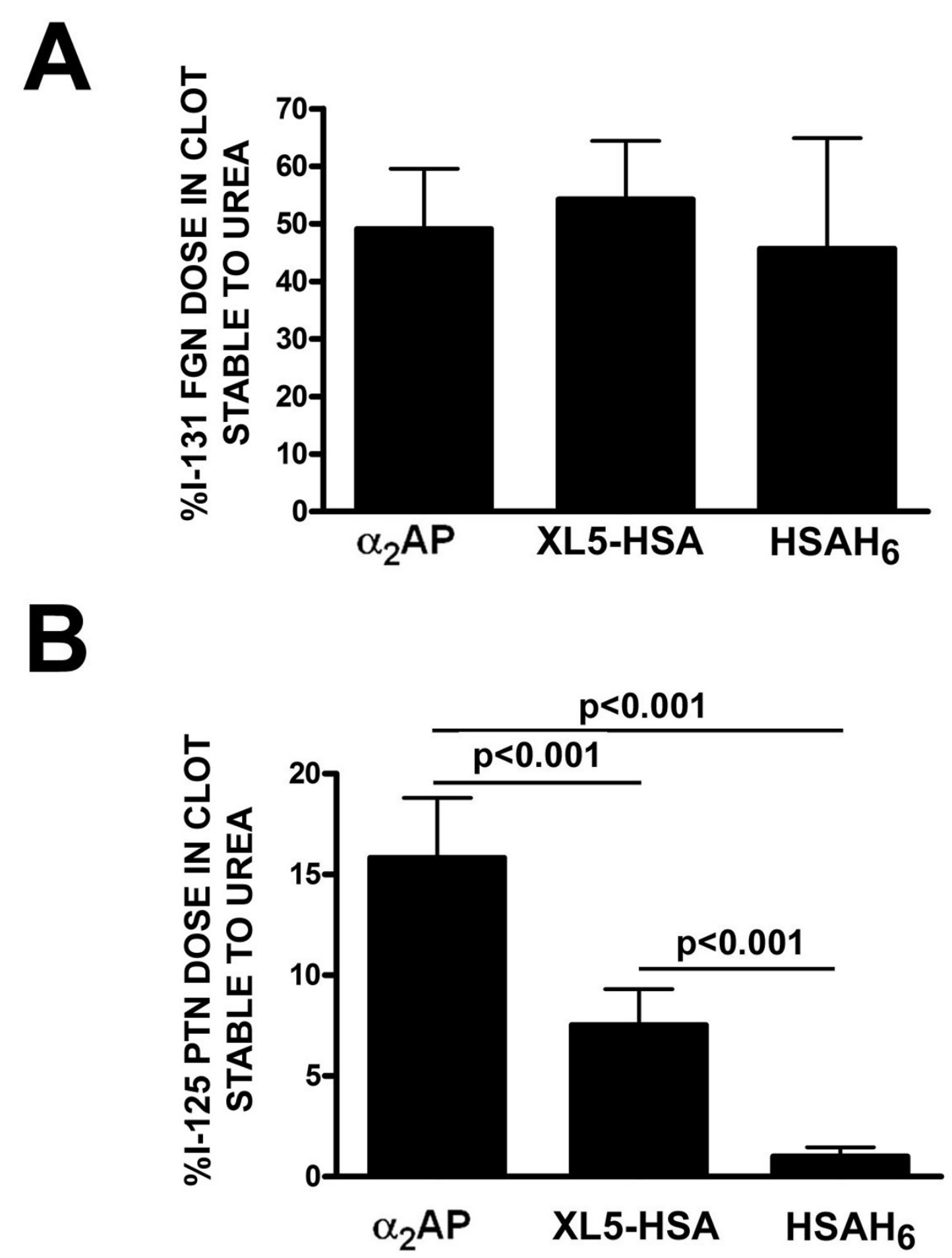

Figure 7 Retention of radiolabeled proteins in experimental thrombi formed in rabbits following extraction in $5.0 \mathrm{M}$ urea. Rabbits were co-injected with ${ }^{131}$ I-fibrinogen and ${ }^{125}$ I-proteins identified in Figure 6 and jugular vein clots were formed as described in "Methods" Clots were $\gamma$-counted at the close of the experiment, and then extracted overnight with $5.0 \mathrm{M}$ urea, the supernatant aspirated, and the clots recounted. The fraction of the total injected radiolabeled protein dose found in the clot after urea extraction is shown for ${ }^{131}{ }^{1}$-fibrinogen, identified by the coinjected ${ }^{125}$ I protein on the $x$ axis in (A) and for ${ }^{125}$-labeled proteins in (B). Differences between ${ }^{131}$ I-fibrinogen among the three groups in (A) are not statistically significant; the extent of statistically significant differences between groups is shown for the data sets linked by horizontal lines in (B). The mean \pm SD of 12 determinations is shown. 
to fibrin in fusion protein XL4-HSA. Although our avoidance of Lys or Arg residues in the fusion motifs was successful in avoiding degradation in each case, only XL5-HSA was clearly superior not only to XL4HSA or XL6-HSA but also to $\alpha_{2} \mathrm{AP}(13-42)-\mathrm{HSA}$.

Although the requirements for optimal substrates of FXIIIa have not been precisely defined, they are thought to involve positioning of a reactive glutamine residue within a highly flexible sequence [36]. Fusion proteins XL4-, XL5-, and XL6-HSA all contained a reactive glutamine at position 2, analogous to Q14, the most reactive glutamine in the native $\alpha_{2} \mathrm{AP}$ sequence. Q14 is more effectively cross-linked by FXIIIa in the major form of $\alpha_{2} \mathrm{AP}$ that circulates in plasma, Asn- $\alpha_{2} \mathrm{AP}$, than in the minor precursor form, Met- $\alpha_{2} A P$, which retains residues 1-12 [37]. Our finding that positioning a hexahistidine tag N-terminal to the FXIIIa substrate motif reduced its activity in fusion proteins XL1- and XL2-HSA was consistent both with this natural example and with the general concept of flexibility of the reactive glutamine.

Previously, we found that $\alpha_{2} \mathrm{AP}(13-42)$-HSA was no more likely to be present in vivo in the rabbit jugular vein model of thrombosis than recombinant HSA [19]. In contrast, XL5-HSA was retained in thrombi in vivo to a significantly greater extent than recombinant HSA in both rabbit and murine models. Its degree of retention was less than that of human $\alpha_{2} \mathrm{AP}$ in both cases, suggesting that there is still room for improvement in defining an optimal sequence to render HSA efficiently cross-linked by factor XIIIa. Nevertheless, this is the first demonstration of targeting of an inactive carrier protein to in vivo clots by an attached transamidation substrate motif, although, as described below, others have shown in vivo clot association of transamidation substrate motif peptides [35] and peptide-contrast agent conjugates [33,34]

The insolubility of cross-linked fibrin in $5.0 \mathrm{M}$ urea is a property that has been known for many years, and indeed is used clinically to diagnose FXIII deficiency [38]. Using this property, we showed that in vivo clotassociated XL5-HSA is urea-insoluble, like the majority of bound fibrin or $\alpha_{2} \mathrm{AP}$, but unlike the majority of bound HSA. Although much indirect or in vitro evidence supports the importance of $\alpha_{2} \mathrm{AP}$ cross-linking to fibrin with respect to clot resistance to fibrinolysis $[22,23,39,40]$, this is to our knowledge the first demonstration of cross-linking of either $\alpha_{2}$ AP protein or an engineered polypeptide into in vivo thrombi. Other groups have used peptides in this regard, but predominantly in an analytical or imaging mode distinct from long-term goal of reducing thrombus size using crosslinkable proteins. Robinson et al. showed that biotinylated $\alpha_{2}$ AP (13-24) peptide became cross-linked to human thrombi embolized into the lungs of ferrets and mice when infused in vivo [35]. Jaffer et al. employed an $\alpha_{2} \mathrm{AP}$ (13-24) peptide linked to a near infrared fluorochrome to image murine thrombi formed following ferric chloride treatment of the femoral vessels [34], while Miserus et al., used a similar $\alpha_{2} \mathrm{AP}$ (13-23) peptide conjugated to a gadolinium-containing contrast agent to visualize murine carotid artery ferric chloride-induced thrombi [33]. While these peptides and peptide-chemical conjugates show great promise for future improved detection of thrombi and stratification of patients, peptides are typically cleared from the circulation with extremely rapid pharmacokinetics. That fusion protein XL5-HSA was found to localize in in vivo thrombi to a greater extent than unmodified recombinant HSA suggests not only its superiority over our previously described $\alpha_{2}$ AP (13-42)-HSA chimera, but also its potential utility in being incorporated as a "Trojan horse" into thrombi, and making them more susceptible to natural or pharmacological thrombolysis.

\section{Conclusions}

Recombinant HSA with a DQMMLPWPAVTLG 4 Y Nterminal extension (XL5-HSA) was more active as a substrate for FXIIIa-mediated cross-linking to either artificial or natural transglutamination partners than other candidate motifs of identical or longer length, with or without an N-terminal His tag. XL5-HSA, unlike $\alpha_{2} \mathrm{AP}(13-42)$ HSA or $\mathrm{H}_{6} \alpha_{2} \mathrm{AP}(13-42)$-HSA, was not subject to detectable proteolysis by $P$. pastoris. Of the proteins tested, XL5HSA was the most effective competitor of $\alpha_{2}$ AP-mediated resistance of fibrin clots to lysis. In contrast to previous results with $\alpha_{2} \mathrm{AP}(13-42)-\mathrm{HSA}$, radiolabeled tracer XL5HSA was found to a greater extent in experimentallyinduced intravascular clots in both murine and rabbit in vivo venous thrombosis models; importantly, the majority of clot-associated XL5-HSA and plasma-derived $\alpha_{2}$ AP, but not recombinant HSA, was shown to be insoluble to 5.0 M urea, suggesting covalent cross-linking. Our results suggest that fusion protein XL5-HSA has been sufficiently optimized over prototype $\alpha_{2} \mathrm{AP}(13-42)$-HSA to warrant in vivo testing as a potential protein drug rendering thrombi more susceptible to natural or pharmacological clot lysis.

\section{Acknowledgements}

The authors thank Sharon Gataiance and Varsha Bhakta for expert technical assistance, and are grateful to Dr. Edward Przydial, University of British Columbia and Canadian Blood Services, for the generous gift of tPA. This study was made possible by a Grant-In-Aid from the Heart and Stroke Foundation of Ontario (award number T6588) to WPS.

\section{Author details}

${ }^{1}$ Department of Pathology and Molecular Medicine, McMaster University, 1200 Main Street West, Hamilton, Ontario, Canada. ${ }^{2}$ Research and Development, Canadian Blood Services, Hamilton, Ontario, Canada.

\section{Authors' contributions}

WPS conceived of the study, secured competitive funding, directed experiments, and wrote the manuscript. LJE-S performed all in vitro and in 
vivo experiments and developed and refined experimental protocols. Both authors participated in editing and revising the manuscript. Both authors read and approved the final manuscript.

Received: 24 August 2011 Accepted: 20 December 2011 Published: 20 December 2011

\section{References}

1. Sheffield WP, McCurdy TR, Bhakta V: Fusion to albumin as a means to slow the clearance of small therapeutic proteins using the Pichia pastoris expression system: a case study. Methods Mol Biol 2005, 308:145-154.

2. Kratz F: Albumin as a drug carrier: design of prodrugs, drug conjugates and nanoparticles. J Control Release 2008, 132(3):171-183.

3. Peters T Jr: Serum albumin. Adv Protein Chem 1985, 37:161-245.

4. Hatton MW, Richardson M, Winocour PD: On glucose transport and nonenzymic glycation of proteins in vivo. J Theor Biol 1993, 161(4):481-490.

5. Chaudhury C, Mehnaz S, Robinson JM, Hayton WL, Pearl DK, Roopenian DC, Anderson $\mathrm{CL}$ : The major histocompatibility complex-related Fc receptor for lgG (FcRn) binds albumin and prolongs its lifespan. J Exp Med 2003, 197(3):315-322.

6. Kim J, Bronson CL, Hayton WL, Radmacher MD, Roopenian DC, Robinson JM, Anderson CL: Albumin turnover: FCRn-mediated recycling saves as much albumin from degradation as the liver produces. Am J Physiol Gastrointest Liver Physiol 2006, 290(2):G352-360.

7. Andersen JT, Daba MB, Sandlie I: FcRn binding properties of an abnormal truncated analbuminemic albumin variant. Clin Biochem 2010, 43(45):367-372.

8. Kobayashi K, Nakamura N, Sumi A, Ohmura T, Yokoyama K: The development of recombinant human serum albumin. Ther Apher 1998, 2(4):257-262.

9. Subramanian GM, Fiscella M, Lamouse-Smith A, Zeuzem S, McHutchison JG: Albinterferon alpha-2b: a genetic fusion protein for the treatment of chronic hepatitis C. Nat Biotechnol 2007, 25(12):1411-1419.

10. Melder RJ, Osborn BL, Riccobene T, Kanakaraj P, Wei P, Chen G, Stolow D, Halpern WG, Migone TS, Wang Q, et al: Pharmacokinetics and in vitro and in vivo anti-tumor response of an interleukin-2-human serum albumin fusion protein in mice. Cancer Immunol Immunother 2005, 54(6):535-547.

11. Huang YJ, Lundy PM, Lazaris A, Huang Y, Baldassarre H, Wang B, Turcotte C, Cote M, Bellemare A, Bilodeau AS, et al: Substantially improved pharmacokinetics of recombinant human butyrylcholinesterase by fusion to human serum albumin. BMC Biotechnol 2008, 8:50.

12. Weimer T, Wormsbacher W, Kronthaler U, Lang W, Liebing U, Schulte S: Prolonged in-vivo half-life of factor VIla by fusion to albumin. Thromb Haemost 2008, 99(4):659-667.

13. Metzner HJ, Weimer T, Kronthaler U, Lang W, Schulte S: Genetic fusion to albumin improves the pharmacokinetic properties of factor IX. Thromb Haemost 2009, 102(4):634-644.

14. Sheffield WP, Mamdani A, Hortelano G, Gataiance S, Eltringham-Smith L, Begbie ME, Leyva RA, Liaw PS, Ofosu FA: Effects of genetic fusion of factor IX to albumin on in vivo clearance in mice and rabbits. $\mathrm{Br} J$ Haematol 2004, 126(4):565-573.

15. Syed S, Schuyler PD, Kulczycky M, Sheffield WP: Potent antithrombin activity and delayed clearance from the circulation characterize recombinant hirudin genetically fused to albumin. Blood 1997, 89(9):3243-3252.

16. Sheffield WP, Eltringham-Smith $L$, Gataiance $S$, Bhakta $V$ : A long-lasting, plasmin-activatable thrombin inhibitor aids clot lysis in vitro and does not promote bleeding in vivo. Thromb Haemost 2009, 101(5):867-877.

17. Marques JA, George JK, Smith IJ, Bhakta V, Sheffield WP: A barbourinalbumin fusion protein that is slowly cleared in vivo retains the ability to inhibit platelet aggregation in vitro. Thromb Haemost 2001, 86(3):902-908.

18. Sheffield WP, Wilson B, Eltringham-Smith $\amalg$, Gataiance $S$, Bhakta V: Recombinant albumins containing additional peptide sequences smaller than barbourin retain the ability of barbourin-albumin to inhibit platelet aggregation. Thromb Haemost 2005, 93(5):914-921.

19. Sheffield WP, Eltringham-Smith $\sqcup$, Gataiance $S$, Bhakta $V$ : Addition of a sequence from alpha2-antiplasmin transforms human serum albumin into a blood clot component that speeds clot lysis. BMC Biotechnol 2009, 9:15.
20. Aoki N: The past, present and future of plasmin inhibitor. Thromb Res 2005, 116(6):455-464.

21. Sakata Y, Aoki N: Significance of cross-linking of alpha 2-plasmin inhibitor to fibrin in inhibition of fibrinolysis and in hemostasis. J Clin Invest 1982, 69(3):536-542

22. Lee KN, Lee SC, Jackson KW, Tae WC, Schwartzott DG, McKee PA: Effect of phenylglyoxal-modified alpha2-antiplasmin on urokinase-induced fibrinolysis. Thromb Haemost 1998, 80(4):637-644.

23. Lee KN, Tae WC, Jackson KW, Kwon SH, McKee PA: Characterization of wild-type and mutant alpha2-antiplasmins: fibrinolysis enhancement by reactive site mutant. Blood 1999, 94(1):164-171.

24. Chuang VT, Otagiri M: Recombinant human serum albumin. Drugs Today (Barc) 2007, 43(8):547-561.

25. Ichinose A, Tamaki T, Aoki N: Factor XIII-mediated cross-linking of NH2terminal peptide of alpha 2-plasmin inhibitor to fibrin. FEBS Lett 1983, 153(2):369-371.

26. Sugimura $Y$, Hosono M, Wada F, Yoshimura T, Maki M, Hitomi K: Screening for the preferred substrate sequence of transglutaminase using a phage-displayed peptide library: identification of peptide substrates for TGASE 2 and Factor XIIIA. J Biol Chem 2006, 281(26):17699-17706.

27. Jobse BN, Sutherland JS, Vaz D, Bhakta V, Sheffield WP: Molecular cloning and functional expression of rabbit alpha2-antiplasmin. Blood Coagul Fibrinolysis 2006, 17(4):283-291.

28. Sheffield WP, Smith IJ, Syed S, Bhakta V: Prolonged in vivo anticoagulant activity of a hirudin-albumin fusion protein secreted from Pichia pastoris. Blood Coagul Fibrinolysis 2001, 12(6):433-443.

29. Wang X, Smith PL, Hsu MY, Ogletree ML, Schumacher WA: Murine model of ferric chloride-induced vena cava thrombosis: evidence for effect of potato carboxypeptidase inhibitor. J Thromb Haemost 2006, 4(2):403-410.

30. Wang X, Smith PL, Hsu MY, Tamasi JA, Bird E, Schumacher WA: Deficiency in thrombin-activatable fibrinolysis inhibitor (TAFI) protected mice from ferric chloride-induced vena cava thrombosis. J Thromb Thrombolysis 2007, 23(1):41-49.

31. Wessler S: Thrombosis in the presence of vascular stasis. Am J Med 1962, 33:648-666.

32. Mosesson MW, Siebenlist KR, Hernandez I, Lee KN, Christiansen VJ, McKee PA: Evidence that alpha2-antiplasmin becomes covalently ligated to plasma fibrinogen in the circulation: a new role for plasma factor XIII in fibrinolysis regulation. J Thromb Haemost 2008, 6(9):1565-1570.

33. Miserus RJ, Herias MV, Prinzen L, Lobbes MB, Van Suylen RJ, Dirksen A, Hackeng TM, Heemskerk JW, van Engelshoven JM, Daemen MJ, et al: Molecular MRI of early thrombus formation using a bimodal alpha2antiplasmin-based contrast agent. JACC CardiovasC Imaging 2009, 2(8):987-996.

34. Jaffer FA, Tung CH, Wykrzykowska JJ, Ho NH, Houng AK, Reed GL, Weissleder R: Molecular imaging of factor XIlla activity in thrombosis using a novel, near-infrared fluorescent contrast agent that covalently links to thrombi. Circulation 2004, 110(2):170-176.

35. Robinson BR, Houng AK, Reed GL: Catalytic life of activated factor XIII in thrombi. Implications for fibrinolytic resistance and thrombus aging. Circulation 2000, 102(10):1151-1157.

36. Cleary DB, Maurer MC: Characterizing the specificity of activated Factor XIII for glutamine-containing substrate peptides. Biochim Biophys Acta 2006, 1764(7):1207-1217.

37. Lee KN, Jackson KW, Christiansen VJ, Chung KH, McKee PA: A novel plasma proteinase potentiates alpha2-antiplasmin inhibition of fibrin digestion. Blood 2004, 103(10):3783-3788.

38. Karimi M, Bereczky Z, Cohan N, Muszbek L: Factor XIII Deficiency. Semin Thromb Hemost 2009, 35(4):426-438

39. Fraser SR, Booth NA, Mutch NJ: The antifibrinolytic function of factor XIII is exclusively expressed through alpha-antiplasmin cross-linking. Blood 2011, 117(23):6371-6374.

40. Matsuno H, Kozawa O, Okada K, Ueshima S, Matsuo O, Uematsu T: Plasmin generation plays different roles in the formation and removal of arterial and venous thrombus in mice. Thromb Haemost 2002, 87(1):98-104.

\section{doi:10.1186/1472-6750-11-127}

Cite this article as: Sheffield and Eltringham-Smith: Incorporation of albumin fusion proteins into fibrin clots in vitro and in vivo: comparison of different fusion motifs recognized by factor XIIla. BMC Biotechnology 2011 11:127. 